\title{
Reinforced Ross operation and intermediate to long term follow up
}

\author{
Awais Ashfaq, Hayden Leeds, Irving Shen, Ashok Muralidaran \\ Section of Pediatric and Congenital Cardiac Surgery, Division of Cardiothoracic Surgery, Department of Surgery, Doernbecher Children's Hospital, \\ Oregon Health \& Science University, Portland, OR, USA \\ Contributions: (I) Conception and design: A Muralidaran, I Shen; (II) Administrative support: A Muralidaran, I Shen; (III) Provision of study materials \\ or patients: A Muralidaran, I Shen; (IV) Collection and assembly of data: A Ashfaq, H Leeds; (V) Data analysis and interpretation: A Ashfaq, H \\ Leeds; (VI) Manuscript writing: All authors; (VII) Final approval of manuscript: All authors. \\ Correspondence to: Ashok Muralidaran, MD. Associate Professor of Surgery and Pediatrics, Pediatric and Congenital Cardiac Surgery, Doernbecher \\ Childrens Hospital, Oregon Health \& Sciences University, Portland, OR, USA. Email: muralida@ohsu.edu.
}

\begin{abstract}
The Ross operation for aortic valve replacement continues to be a controversial option because of concerns related to late autograft dilation and progressive neo-aortic regurgitation. We described a technique in 2005 to address this problem, in which we place the entire autograft in a Dacron tube which makes it theoretically unlikely, if not impossible, for it to dilate-the reinforced Ross procedure. Since 2004, we have operated on 25 patients using this technique. Median length of follow-up in our cohort was 6 years, with 14 patients having 5 years or more of follow-up. Our data demonstrate the externally supported, or reinforced Ross technique using a straight graft is a safe and effective technique in older children, adolescents, and young adult patients. At intermediate follow-up, patients who underwent a reinforced Ross technique were less likely to have neoaortic root dilatation.
\end{abstract}

Keywords: Aortic valve/surgery; blood vessel prosthesis implantation/methods; dilation, pathologic/prevention and control; heart valve diseases/surgery

Submitted Aug 29, 2019. Accepted for publication Sep 17, 2019.

doi: $10.21037 /$ jtd.2019.09.53

View this article at: http://dx.doi.org/10.21037/jtd.2019.09.53

\section{Introduction}

The Ross operation for aortic valve replacement continues to be a controversial option because of concerns related to late autograft dilation and progressive neo-aortic regurgitation. Patients with bicuspid aortic valves and dilated ascending aortas or patients with dilated aortic roots and primarily aortic insufficiency have been considered the highest risk groups for autograft dilation and neoaortic insufficiency in some series $(1,2)$. As a result, there have been reports of "wrapping" the autograft with pericardium or ascending aorta (inclusion technique) or with Dacron or Teflon felt at the annular level, but these do not tend to provide support for the entire autograft (3-5). Autograft dilation, when occurs, is not limited to the annulus, and involves the entire autograft. We described a technique in 2005 (6) to address this problem, in which we place the entire autograft in a Dacron tube which makes it theoretically unlikely, if not impossible, for it to dilate-the reinforced Ross procedure.

\section{Technique}

\section{Cardiopulmonary bypass and aortic valve inspection}

The operation is performed via median sternotomy, on moderate hypothermic cardiopulmonary bypass with aortic and bicaval cannulation. After cardioplegic arrest, the aorta is transected just above the sinotubular junction and the aortic valve is inspected and the aortic annulus is sized.

\section{Autograft barvesting}

Before instituting cardiopulmonary bypass, we use a Hemashield sizer to estimate the external diameter of the pulmonary artery at the level of the annulus. After 


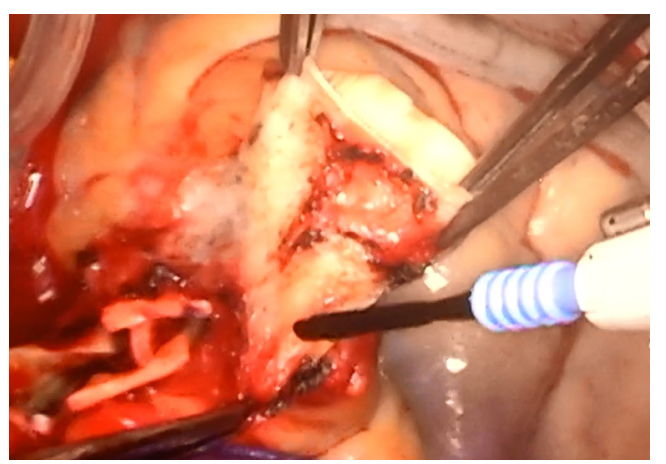

Figure 1 Posterior autograft mobilization involving anterior retraction and close dissection of the pulmonary root.

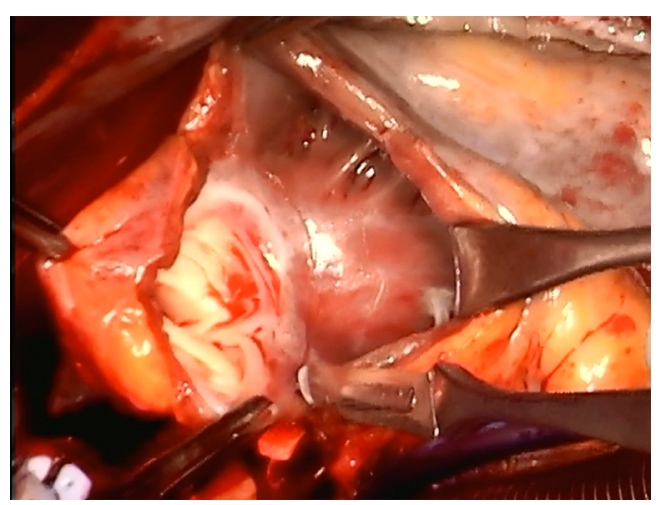

Figure 2 Posterior infundibular scoring using a \#15 blade. Care is made to score the intima of the posterior infundibulum at the desired distance from the leaflets, guiding its transection.

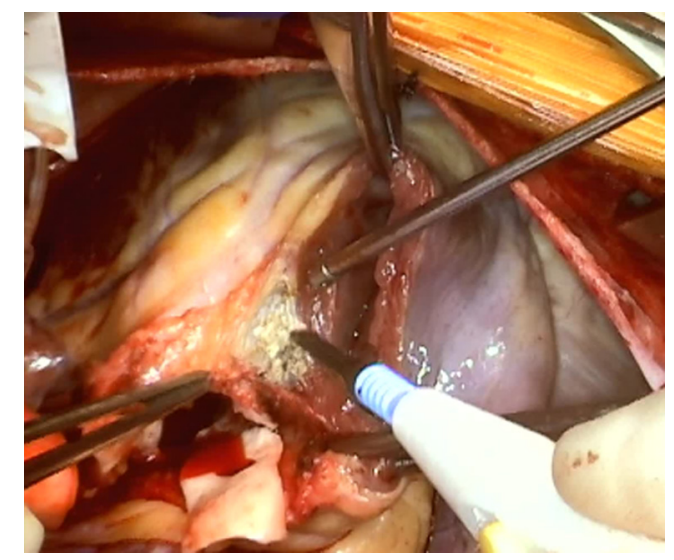

Figure 3 Autograft muscular bed cauterization to ensure adequate hemostasis. inspecting the aortic valve as mentioned above, the main pulmonary artery is transected just proximal to the left and right pulmonary artery bifurcation. The pulmonary valve is inspected and assessed for use as the autograft valve.

Once the decision to proceed with the Ross operation has been made, we re-inspect the aortic root. The left and right coronary buttons are mobilized as this facilitates the next step of the procedure. The pulmonary root is now dissected circumferentially, taking care to avoid the left main coronary artery and the left anterior descending artery. Again, mobilizing the coronary buttons prior this step facilitates the ease and safety of dissection. The aortic and pulmonary roots are most densely adherent at the level of the commissure between the right and left coronary leaflets where care must be taken to err on the aortic side. Safe posterior autograft mobilization is accomplished by anterior retraction of the pulmonary root by the assistant and by keeping the dissection close to the pulmonary root (Figure 1). Dissection proceeds till one reaches an external plane corresponding to the nadir of the leaflets as viewed from inside the autograft.

A right angled clamp is passed via the pulmonary annulus and the tip positioned a few millimeters below the nadir of the anterior leaflet to guide the right ventriculotomy. The right ventricular outflow tract is opened transversely and under direct visualization, this incision is carried out circumferentially. Care is taken to stay at a uniform depth of 2 to $3 \mathrm{~mm}$ below the nadir of the leaflets and to not inadvertently slice into the intercommissural triangles. Hence, the infundibular muscle "skirt" has differing heights, more below the commissural triangles and less under the leaflet nadirs. We routinely use a \#15 blade to score the intima of the posterior infundibulum at the desired distance from the leaflets to guide its transection (Figure 2). Once the autograft is explanted, the muscular autograft bed is well cauterized as bleeding in this area will be difficult to control at a later stage of the procedure (Figure 3). Also, one can administer a "test-dose" of cardioplegia directly into the left coronary ostium to look for injured or transected septal perforator arteries that are best repaired at this point in the procedure.

\section{Autograft preparation and reimplantation}

We pay great attention to carefully trim all excess muscular and fatty tissue from the right ventricular outflow tract/free wall 


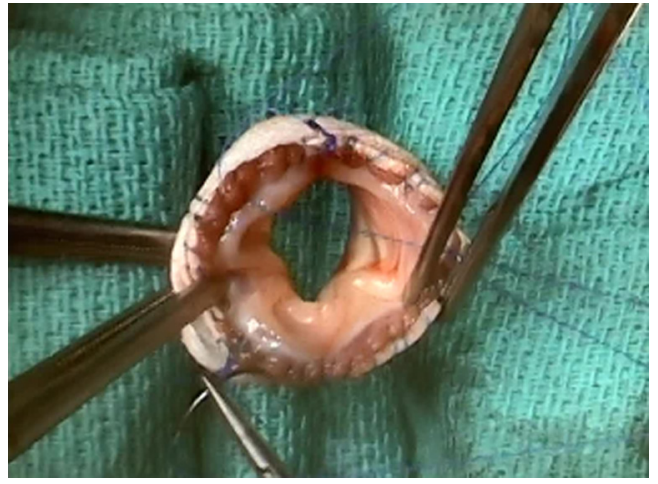

Figure 4 The autograft is proximally fixed to the graft with 3 monofilament sutures under each leaflet nadir. A continuous suture is then run from each leaflet.

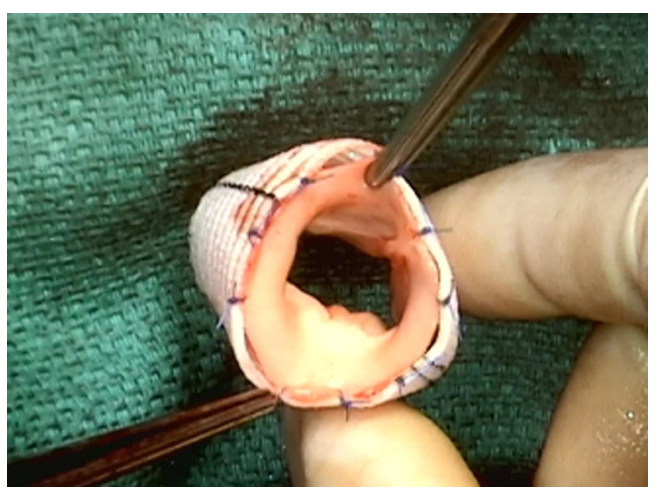

Figure 5 Two interrupted sutures are placed between each commissural suture at the distal end of the composite autograft.

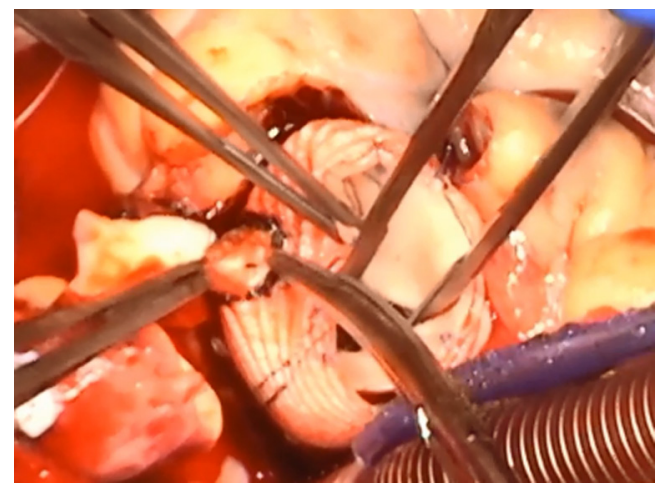

Figure 6 Creation of a buttonhole in the autograft root by drawing it out of a hole made in the Dacron graft.

portion of the autograft. This avoids focal inward bulging of the autograft once placed inside a Dacron sleeve. Distally, the autograft is trimmed to ensure equal tissue height above the top of the commissural pillars. The autograft is then sized using Hegar dilators.

We size the Dacron graft 3 to $4 \mathrm{~mm}$ greater than the internal diameter of the autograft and use a straight graft. Marks are placed at 120 degrees on the Dacron graft to indicate the orientation of the commissures. We have not used the Gel weave Valsalva graft and do not routinely prepare the graft with albumin as had been instructed by some surgeons. The autograft is proximally fixed into the graft with 3 monofilament sutures under each leaflet nadir. This suture line is then run continuously from one nadir to the next and tied (Figure 4). This leaves behind three towers of knots that are a visual reminder of the nadir of the leaflets. Distally, the height of the autograft is assessed and the Dacron graft cut to the appropriate length to keep the autograft stretched to a natural height. Each distal commissure is tacked with an interrupted monofilament suture to the distal end of the Dacron. Then two additional sutures are placed between each commissure resulting in a total of nine interrupted sutures (Figure 5). We test the autograft valve with saline injection to check for competence.

\section{Aortic root preparation and autograft implantation}

The aortic valve is resected and the remaining aortic root tissue including the non-coronary sinus wall and the native commissural pillars are all excised. We then place three 4-0 polypropylene sutures 120 degrees apart starting from the nadir of the original left coronary sinus in the aortic root and pass them through the corresponding spots on the base of the Dacron-reinforced composite autograft to avoid misalignment and distortion. The presence of the "knot towers" mentioned earlier facilitates proper placement of these sutures at the spots corresponding to the nadir of the composite autograft leaflets. We then continuously suture the autograft to the aortic root from one leaflet nadir to the next. Care is taken to not damage the neo-aortic valve leaflets by avoiding deep bites in the proximal end of the reinforced graft to include the native autograft tissue.

Using ophthalmic cautery, a hole is made in the Dacron graft for reimplantation of the left coronary button. A corresponding portion of the autograft wall is pinched through this Dacron opening and a circular piece is resected (Figure 6). Once this is done, we reimplant the left coronary button incorporating all three layers-coronary button, autograft and Dacron using continuous monofilament sutures. Similarly, a hole or a slit is made for the right 
coronary button and it is re-implanted. Attention is made to position this higher and to avoid any future kinking with cardiac distention.

\section{Distal anastomosis and homograft implantation}

The distal suture line between the chosen right ventricle to pulmonary artery (RV-PA) conduit and the distal end of the main pulmonary artery is made using a continuous monofilament suture. Then the ascending aorta is anastomosed to the reinforced autograft using continuous monofilament suture incorporating both layers on the composite autograft. If the ascending aorta is dilated or aneurysmal, it can be replaced with a graft.

Then the right ventricular outflow tract is anastomosed to the proximal RV-PA conduit with running monofilament sutures. Ventilation is resumed, de-airing maneuvers are performed and cross-clamp is removed.

\section{Results}

Since 2004, we have operated on 25 patients of which 20 were male $(80 \%)$. Median age at surgery was 29 years (range, 12-58 years). Twenty-three patients (92\%) had a bicuspid aortic valve. Indications for surgery included aortic stenosis (AS, $n=6$ ), aortic insufficiency (AI, n=7) and mixed disease $(n=12)$. Seven of the 25 were reoperations. Prior surgeries included aortic valvotomy $(n=4)$, open commissurotomy $(\mathrm{n}=1)$, coarctation and atrioventricular (AV) canal repair $(\mathrm{n}=1)$, and aortic root replacement with homograft $(n=1)$. The average size of the Dacron graft was $28 \mathrm{~mm}$. The average cardiopulmonary bypass time for this operation was 228.4 minutes with an average cross-clamp time of 174.2 minutes.

Seven patients had preoperative ascending aortic dilation requiring simultaneous ascending aortic replacement. No patient had more than mild AS or AI on immediate postoperative transesophageal echocardiogram. Five patients (20.8\%) underwent subsequent aortic valve replacement and $1(4.2 \%)$ had aortic valve repair. Median time to reintervention was 2 years. All aortic re-interventions were performed from patients early in our experience (2004-2007). Three of these patients required aortic valve replacement for progressively worsening AI. One of these three patients also required replacement of their ascending aorta secondary to aortic dilation. One patient required aortic valve replacement secondary to endocarditis, as well as mechanical pulmonary valve replacement in the setting of severe pulmonary stenosis. Another patient required aortic valve repair and conduit replacement due to worsening AI and conduit stenosis. The last patient required an aortic valve replacement and conduit revision secondary to aortic root dehiscence and pectus excavatum causing conduit compression.

Two patients have moderate and one patient has greater than moderate AI on last echocardiogram. One patient had mild aortic root dilation $(4.1 \mathrm{~cm})$ on last follow-up, and there was no ascending aortic dilation $(>4.5 \mathrm{~cm})$. Median follow up was 6 years. Fourteen patients had 5 years or more of follow-up. All patients were alive at time of last follow up.

\section{Comments}

The most prominent, long-term complication after the Ross procedure seems to be the risk of autograft dilatation (7). To prevent this complication, we performed our first modified Ross operation in October 2004 (6). Since then, there have been subsequent reports in the literature discussing modifications of our technique. In one report, the manner of a coronary button anastomosis is different (8), and in the other report, a sinus of Valsalva graft is used to allow for a more normal sinus area above the valve $(9,10)$. Routinely, we have seen a thin rim of fluid surrounding the autograft but have not encountered any major distortions. This seems to get absorbed over time, over a period of few weeks and have not created any "holes" in the Dacron either. Problematic fluid collections/hematomas seem to happen more in instances where a sinus of Valsalva graft is used, since there is a bigger potential space between the autograft and the Dacron.

We do not have a "hard" lower age limit but usually restrict to early teenagers that have almost completed their somatic growth. By this time, usually their internal organs have achieved adult dimension, although they may still have some skeletal growth left. Our cutoff for pulmonary autograft is a pulmonary annular dimension of $2 \mathrm{~cm}$. We have not had any bicuspid pulmonary valves in our experience. Generally, we would not consider performing the Ross procedure in this setting and would only consider it if other aortic valve replacement options were contraindicated. We have only used echocardiogram for follow up on a routine basis and have not crafted a protocolized approach to postoperative blood pressure management since we feel the reinforcement protects the autograft. However, we prefer to treat any patients with 
persistent hypertension above $140 \mathrm{mmHg}$.

Our data demonstrate the externally supported, or reinforced Ross technique using a straight graft is a safe and effective technique in older children, adolescents, and young adult patients. At intermediate follow-up, patients who underwent a reinforced Ross technique were less likely to have neoaortic root dilatation. However, further studies are needed to evaluate the long-term durability of this technique, particularly in regards to the development of significant aortic regurgitation, rate of reintervention, and application to younger and smaller patients.

\section{Acknowledgments}

Funding: None.

\section{Footnote}

Provenance and Peer Review: This article was commissioned by the Guest Editor (Raghav A. Murthy) for the series "Management of Congenital Heart Disease" published in Fournal of Thoracic Disease. The article was sent for external peer review organized by the Guest Editor and the editorial office.

Conflicts of Interest: The series "Management of Congenital Heart Disease" was commissioned by the editorial office without any funding or sponsorship. The authors have no other conflicts of interest to declare.

Ethical Statement: The authors are accountable for all aspects of the work in ensuring that questions related to the accuracy or integrity of any part of the work are appropriately investigated and resolved.

Open Access Statement: This is an Open Access article distributed in accordance with the Creative Commons Attribution-NonCommercial-NoDerivs 4.0 International License (CC BY-NC-ND 4.0), which permits the non- commercial replication and distribution of the article with the strict proviso that no changes or edits are made and the original work is properly cited (including links to both the formal publication through the relevant DOI and the license). See: https://creativecommons.org/licenses/by-nc-nd/4.0/.

\section{References}

1. Kouchoukos NT, Masetti P, Nickerson NJ, et al. The Ross procedure: long-term clinical and echocardiographic follow-up. Ann Thorac Surg 2004;78:773-81; discussion 773-81.

2. Luciani GB, Casali G, Favaro A, et al. Fate of the aortic root late after Ross operation. Circulation 2003;108 Suppl 1:II61-7.

3. David TE, Omran A, Ivanov J, et al. Dilation of the pulmonary autograft after the Ross procedure. J Thorac Cardiovasc Surg 2000;119:210-20.

4. Elkins RC. The Ross operation: a 12-year experience. Ann Thorac Surg 1999;68:S14-8.

5. Skillington PD, Fuller JA, Grigg LE, et al. Ross procedure. Inserting the autograft using a fully supported root replacement method; techniques and results. J Heart Valve Dis 1999;8:593-600.

6. Slater M, Shen I, Welke K, et al. Modification to the Ross procedure to prevent autograft dilatation. Semin Thorac Cardiovasc Surg Pediatr Card Surg Annu 2005:181-4.

7. Ungerleider RM, Ootaki Y, Shen I, et al. Modified Ross procedure to prevent autograft dilatation. Ann Thorac Surg 2010;90:1035-7; discussion 1037.

8. Koul B, Al-Rashidi F, Bhat M, et al. A modified Ross operation to prevent pulmonary autograft dilatation. Eur J Cardiothorac Surg 2007;31:127-8.

9. Carrel T, Schwerzmann M, Eckstein F, et al. Preliminary results following reinforcement of the pulmonary autograft to prevent dilatation after the Ross procedure. J Thorac Cardiovasc Surg 2008;136:472-5.

10. Gebauer R, Cerny S. A modification of the Ross procedure to prevent pulmonary autograft dilatation. Eur J Cardiothorac Surg 2009;36:195-7.
Cite this article as: Ashfaq A, Leeds H, Shen I, Muralidaran A. Reinforced Ross operation and intermediate to long term follow up. J Thorac Dis 2020;12(3):1219-1223. doi: 10.21037/ jtd.2019.09.53 